\title{
Acute, Reversible Autonomic Nervous System Abnormalities in Juvenile Insulin-Dependent Diabetes
}

\author{
A Pupillographic Study
}

\author{
Á. B. Hreidarsson \\ Second University Clinic of Internal Medicine, Kommunehospitalet, Aarhus, Denmark
}

\begin{abstract}
Summary, Autonomic nervous function was studied by infrared TV-pupillography in nine insulin-dependent diabetic subjects with 0 to 3 years duration of diabetes, during poor and good metabolic control. During poor control there was no change in the latency time, the maximal contraction velocity or the amplitude of the light response, whereas the redilatation time was prolonged by $28 \%$, from $2.26 \pm 0.27$ to $2.90 \pm 0.58 \mathrm{~s}$ (mean $\pm \mathrm{SD})(2 \mathrm{p}=0.012)$. The pupil size after adaptation to darkness was unchanged, but the light induced pupillary unrest was reduced by $35 \%$ from $1.68 \pm 0.62$ to $1.10 \pm$ $0.36 \mathrm{~mm}^{2}(2 \mathrm{p}=0.0037)$, and the degree of miosis in continuous illumination was reduced by $47 \%$ from $0.32 \pm 0.13$ to $0.17 \pm 0.08(2 p=0.0011)$, during metabolic derangement. The study has thus demonstrated reversible changes in autonomic nervous function, which are related to the diabetic metabolic state and thereby analogous to the previously well established reversible functional changes in the somatic nervous system in early diabetes.
\end{abstract}

Key words: Autonomic nervous system, reversible nervous abnormalities, insulin-dependent diabetes, diabetic neuropathy, pupil, pupillography.

It is well known that in patients with diabetes mellitus neurological symptoms may be precipitated after periods of poor blood glucose control. The symptoms often disappear with insulin treatment $[17,22,25]$. Abnormalities of the nervous system in diabetics can be detected by neurophysiological measurements a long time before symptoms of diabetic neuropathy appear, and this is true for both the somatic $[8,32$, $33,34]$ and the autonomic nervous system $[4,13]$. Peripheral nervous abnormalities such as decreased motor conduction velocity and prolonged vibratory perception during ischaemia can be provoked or reversed within days to weeks by altering the diabetic metabolic state $[7,9,31,33]$, but a similar metabolic influence on the autonomic nervous system has not been demonstrated. It has indeed been suggested that autonomic nerves may be less susceptible to metabolic damage than somatic fibres [2].

The pupil of the eye offers an excellent opportunity to study the state of the autonomic nervous system [20]. The pupil is easily accessible for measurement and stimulation, and using modern techniques with quantitative and reproducible stimuli very precise information can be obtained.

The purpose of the present investigation was to try to resolve the question of possible metabolic influence on the autonomic nervous system by examining recently diagnosed insulin-dependent diabetic subjects with infrared TV-pupillography under controlled, but varying metabolic circumstances.

\section{Material and Methods}

\section{Patients}

One female and eight male insulin-dependent diabetics, aged 20 to 36 years, were studied (Table 1). Their visual acuity was at least $6 / 6$. Three patients were studied before and after treatment of their newly diagnosed disease. In the remaining six patients with a duration of diabetes of three years or less, poor metabolic control was achieved by withdrawal of insulin treatment for three days. All patients were examined on several occasions, but only results obtained during the individual's poorest and best metabolic control were used in the analysis. These extremes were defined as the days with highest and lowest blood glucose levels, respectively, and were at most eight weeks apart. The average of non-fasting values obtained at 1100 and $1700 \mathrm{~h}$ was used.

In four patients the best control preceded the poor control day. None of the patients received any drug other than insulin:, Fully informed consent was obtained from all patients studied.

\section{Methods}

Pupillography. Measurements of the area of the left pupil were performed with an infrared sensitive TV-camera (Iriscorder, Hamamatsu TV Corporation, Hamamatsu, Japan), and after 
Table 1. Clinical and biochemical details of the 9 insulin-dependent diabetics studied during best and worst metabolic condition. $\Delta$ denotes change from best to poor control

\begin{tabular}{|c|c|c|c|c|c|c|c|c|}
\hline \multirow[t]{2}{*}{ Sex } & \multirow[t]{2}{*}{$\begin{array}{l}\text { Age } \\
\text { (years) }\end{array}$} & \multirow{2}{*}{$\begin{array}{l}\text { Diabetes } \\
\text { duration } \\
\text { (months) }\end{array}$} & \multicolumn{3}{|c|}{$\begin{array}{l}\text { Ischaemic vibratory perception } \\
\text { response } \mathrm{V} / \mathrm{min}\end{array}$} & \multicolumn{3}{|c|}{ Blood glucose $\mathrm{mg} / 100 \mathrm{ml}$} \\
\hline & & & Poor & Best & $\Delta$ & Poor & Best & $\Delta$ \\
\hline $\mathbf{F}$ & 21 & 0 & 0.43 & 1.33 & -0.90 & 372 & 162 & 210 \\
\hline M & 29 & 0 & 0.83 & 2.00 & -1.17 & 392 & 135 & 257 \\
\hline M & 30 & 0 & 1.03 & 2.00 & -0.97 & 409 & 128 & 281 \\
\hline $\mathbf{M}$ & 31 & 34 & 0.87 & 0.97 & -0.10 & 306 & 181 & 125 \\
\hline M & 24 & 34 & 0.87 & 1.30 & -0.43 & 263 & 155 & 108 \\
\hline M & 36 & 9 & 1.00 & 1.67 & -0.67 & 306 & 84 & 222 \\
\hline $\mathrm{M}$ & 20 & 10 & 0.70 & 1.67 & -0.97 & 387 & 90 & 297 \\
\hline $\mathrm{M}$ & 26 & 22 & 1.27 & 2.00 & -0.73 & 416 & 208 & 208 \\
\hline $\mathbf{M}$ & 22 & 36 & 0.87 & 2.50 & -1.63 & 373 & 148 & 225 \\
\hline Mean & 26 & 16 & 0.87 & 1.72 & -0.84 & 358 & 143 & 215 \\
\hline $\mathrm{SD}$ & & & 0.24 & 0.46 & & 53 & 39 & \\
\hline SEM & & & & & 0.15 & & & 21 \\
\hline
\end{tabular}

analogue-to-digital conversion (Schlumberger, Solarthron, A 210 digital voltmeter) data were handled off-line on a digital computer (CDC Cyber 173 at the Regional EDB-Centre, Aarhus University). The light stimulus was provided by a photostimulator emitting a convergent beam of yellow-green light with a diameter of one mm when reaching the plane of the right pupil (the so-called open loop approach). A more detailed description of the equipment has been published elsewhere [11]. The pupillographic investigation took place in a completely dark room.

The following measures of pupillary function were obtained:

Light response to a square wave increase in the light intensity from 1 to $26 \mu$ Lumen for $256 \mathrm{~ms}$. This was repeated several times with at least $15 \mathrm{~s}$ between each light stimulus. The responses were recorded over $5 \mathrm{~s}$ each with a $100 \mathrm{~Hz}$ sampling rate and averaged (Fig. 1).

The following response parameters were used: latency time in $\mathrm{ms}$, maximal contraction velocity in $\mathrm{mm}^{2} / \mathrm{s}$, response amplitude in $\mathrm{mm}^{2}$ and the redilatation time (the time in $\mathrm{ms}$ from start of the light pulse until the pupil had regained $75 \%$ of its initial size was chosen, normal value $2.72 \pm 0.56 \mathrm{~s}$ (mean $\pm \mathrm{SD}$ ), day to day variation $17.6 \%$ (coefficient of variation), (these and the normal values given below are from our laboratory)).

Pupil Size. After adaptation to complete darkness for $15 \mathrm{~min}$ the size of the pupil was measured at $10 \mathrm{~Hz}$ sampling rate for several periods of $15 \mathrm{~s}$ each and averaged.

Illuminated Pupil Size. Performed as for pupil size. The recordings were started $90 \mathrm{~s}$ after initiation of $512 \mu \mathrm{Lumen}$ continuous illumination. The fractional reduction in pupil size (the degree of miosis) caused by continous illumination was calculated (normal value $0.34 \pm 0.10$, day to day variation $19.7 \%$ )

Hippus or Pupillary Unrest was measured during darkness and continuous illumination. The pupil is always undergoing irregular variations in size, these variations are minimal in darkness, but are greatly accentuated by illumination [20]. Figure 2 shows an example of these fluctuations in darkness and in continuous light. The standard deviation of the above mentioned continuous measurements of pupil size was calculated by the computer and used to express the degree of variation in the area, that is pupillary unrest, in darkness and during constant illumination. The total variation within periods of $15 \mathrm{~s}$ and the variation around the regression line within periods of $5 \mathrm{~s}$ were both calculated. The variation within the longer periods is more sensitive to trends and larger shifts in pupil area and is always higher than that of the shorter periods which mainly measure the small and rapid fluctuations. (Normal values for unrest during illumination $1.65 \pm 0.58$ and $0.86 \pm 0.39 \mathrm{~mm}^{2}$ within intervals of $15 \mathrm{~s}$ and $5 \mathrm{~s}$ respectively, and day to day variation $20.9 \%$ and $16.3 \%$, respectively).

Biothesiometry. As a measure of a somatic nervous function known to be reversible the ischaemic vibratory perception threshold [31] was estimated on the great toe at $100 \mathrm{~Hz}$ by means of a biothesiometer with variable amplitude (expressed in volts, range 0 to 50 volts, Bio-Medical Instrument Corporation, Chagrin Falls, Ohio). Ischaemia was achieved by inflating a cuff above the knee to a pressure above $230 \mathrm{mmHg}$. Repeated measurements were made every five min during ischaemia either for $30 \mathrm{~min}$ or until the threshold was above 50 volts. The result is expressed by the ratio volts/min at termination (see Fig. 3). Abnormal values for this ischaemic vibratory perception response are $<50 / 25$ $\mathrm{V} / \mathrm{min}$, i. e. $<2 \mathrm{~V} / \min [31,33]$.

Laboratory Investigations. Plasma glucose and 3-hydroxybutyrate concentrations were measured by enzymatic methods $[3,19]$. Total $\mathrm{CO}_{2}$, urea, sodium and potassium were measured by standard autoanalyser techniques. The average of values obtained at 1100 and $1700 \mathrm{~h}$ was used to express the biochemical status. (The coefficient of variation for these blood glucose measurements was $23.5 \%$ ). In the three newly diagnosed diabetics the biochemical results obtained at admission were used.

Statistical Analysis. Student's t-test for paired samples and the correlation coefficient, $r$, were used for the statistical evaluation, $2 p$ $<0.05$ being considered significant. Results during good and poor control are given in terms of group mean $\pm S D$, and the change during poor control is expressed in terms of the mean difference (worst minus best) $\pm \mathrm{SEM}$.

\section{Results}

The individual blood glucose values are shown in Table 1 . The mean 3-hydroxybutyrate concentration during best control was $0.10 \pm 0.07$ and during worst 


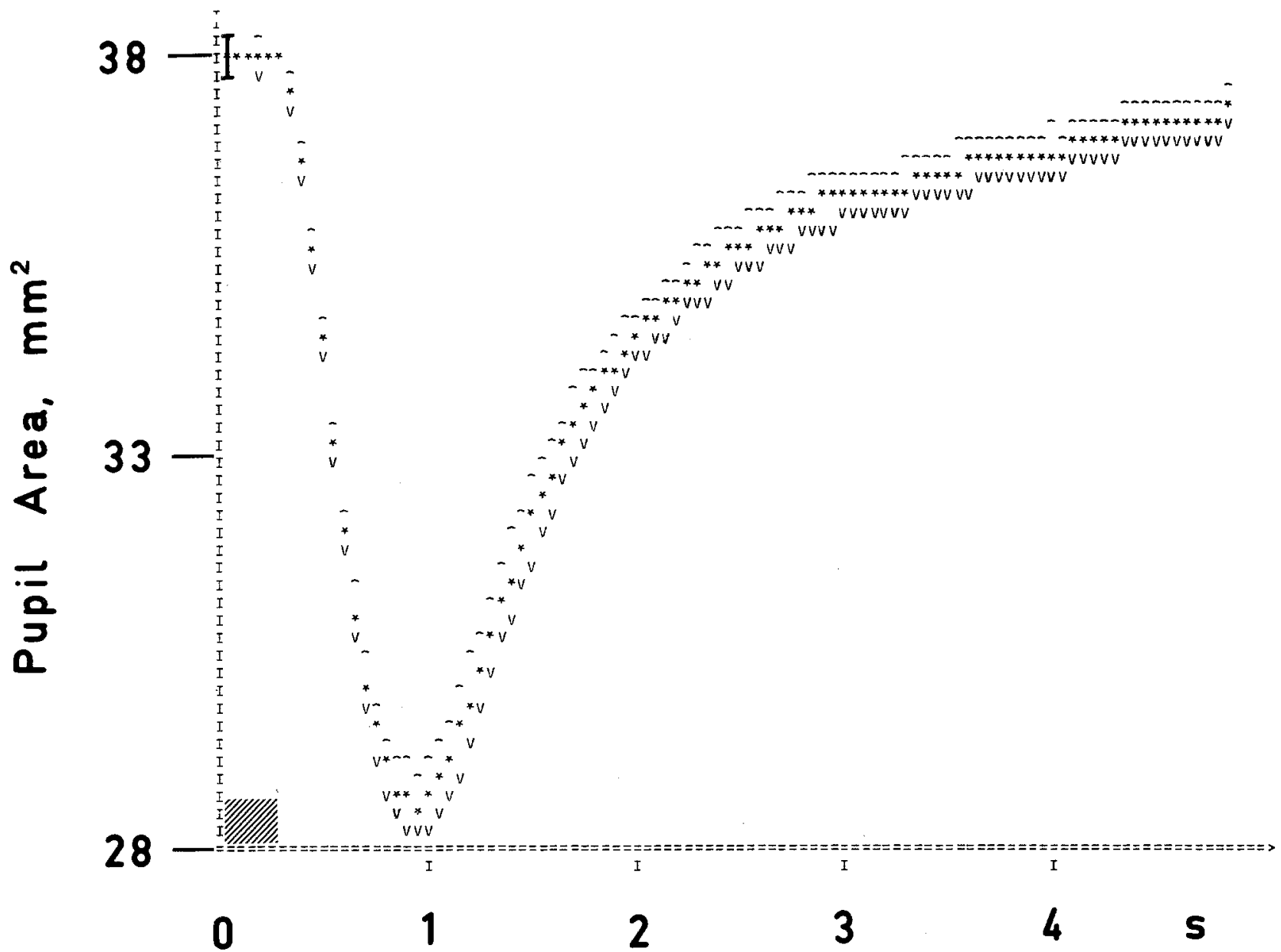

Fig. 1. Computer drawing of the light response of the pupil. Ten consecutive responses are transferred vertically to a common starting

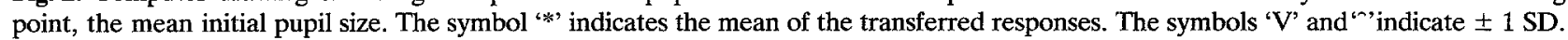
The vertical bar indicates the SD of the mean initial pupil size. The shaded area in the lower left corner indicates the $256 \mathrm{~ms}$ light stimulus

control $1.02 \pm 0.94 \mathrm{mmol} / \mathrm{l}$. Only two of the nine patients were slightly acidotic on the day of worst control, their total $\mathrm{CO}_{2}$ values being 14 and $17 \mathrm{mmol} / \mathrm{l}$. There was no significant change in the blood urea level. Serum potassium concentration was unchanged, and the serum sodium level was lowered by $4 \pm 1 \mathrm{mmol} / \mathrm{l}$ during worst control from $139 \pm$ $2 \mathrm{mmol} / 1$ during best control.

Values of the light response and pupil measurements in darkness are given in Table 2. There were no changes in latency time, maximal contraction velocity, or amplitude of the light response during poor metabolic control, whereas redilatation to $75 \%$ of the initial pupil size occurred significantly later during poor metabolic control $(2 \mathrm{p}=0.012)$. There was no change in pupil size in darkness, but the illuminated pupil size was significantly larger during poor metabolic control $(2 \mathrm{p}=0.0022)$.

During best control the relative reduction in pupil size caused by continuous illumination (the degree of

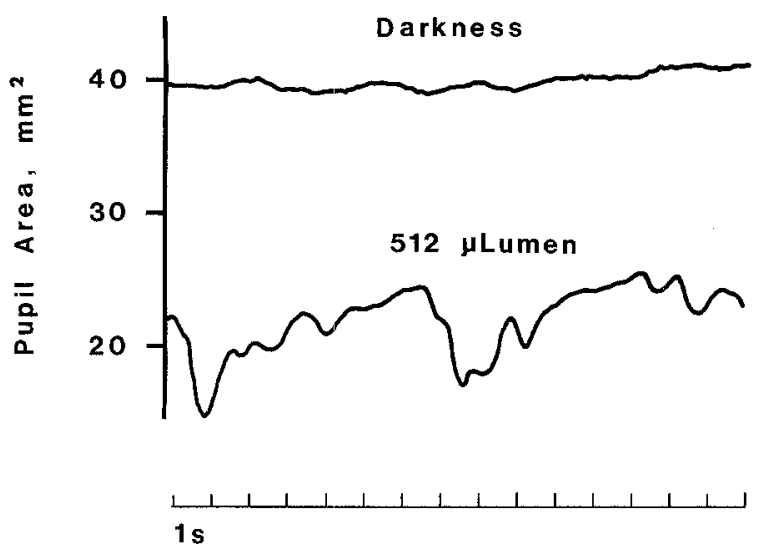

Fig. 2. Pupillary unrest. Examples of pen recorder tracings of the pupil area in a patient during good control, in darkness and in 512 $\mu$ Lumen continuous light. The mean pupil size in this example is $40 \mathrm{~mm}^{2}$ in darkness and $22 \mathrm{~mm}^{2}$ in light. The fractional reduction or steady state miosis is thus $18 / 40=0.45$. The unrest in darkness during the $15 \mathrm{~s}$ was $0.60 \mathrm{~mm}^{2}$ and in light $2.55 \mathrm{~mm}^{2}$. The corresponding average values for the three $5 \mathrm{~s}$ periods, corrected for trend, were 0.23 and $1.62 \mathrm{~mm}^{2}$, respectively 
Table 2. Results of the pupil's response to a short light stimulus, and pupil measurements in darkness from a group of 9 insulin-dependent diabetics during extremes of metabolic control. Results are given as mean \pm SD and mean difference (poor minus best) \pm SEM. NS, not significant

\begin{tabular}{|c|c|c|c|c|c|c|}
\hline & \multicolumn{4}{|l|}{ Light response } & \multicolumn{2}{|c|}{ The pupil in darkness } \\
\hline & $\begin{array}{l}\text { Latency time, } \\
\text { ms }\end{array}$ & $\begin{array}{l}\text { Maximal contrac- } \\
\text { tion velocity, } \\
\mathrm{mm}^{2} / \mathrm{s}\end{array}$ & $\begin{array}{l}\text { Response } \\
\text { amplitude, } \\
\mathrm{mm}^{2}\end{array}$ & $\begin{array}{l}75 \% \text { redilatation } \\
\text { time, } \mathrm{s}\end{array}$ & $\begin{array}{l}\text { Pupil size in } \\
\text { darkness, } \mathrm{mm}^{2}\end{array}$ & $\begin{array}{l}\text { Pupillary unrest } \\
\text { in darkness, } \mathrm{mm}^{2} \\
\text { (15 s periods) }\end{array}$ \\
\hline $\begin{array}{l}\text { Poor control } \\
\text { mean } \pm \mathrm{SD}\end{array}$ & $237 \pm 24$ & $42.7 \pm 8.7$ & $11.9 \pm 2.5$ & $2.90 \pm 0.58$ & $37.0 \pm 7.0$ & $0.75 \pm 0.33$ \\
\hline $\begin{array}{l}\text { Best control } \\
\text { mean } \pm S D \\
\triangle \text { Poor control }\end{array}$ & $230 \pm 23$ & $42.6 \pm 11.1$ & $11.2 \pm 2.9$ & $2.26 \pm 0.27$ & $37.2 \pm 6.0$ & $0.65 \pm 0.11$ \\
\hline mean $\pm \mathrm{SEM}$ & $7 \pm 8$ & $0.1 \pm 2.8$ & $0.7 \pm 0.8$ & $0.64 \pm 0.19$ & $-0.2 \pm 0.9$ & $0.10 \pm 0.30$ \\
\hline Significance & NS & NS & NS & $2 P=0.012$ & NS & NS \\
\hline
\end{tabular}

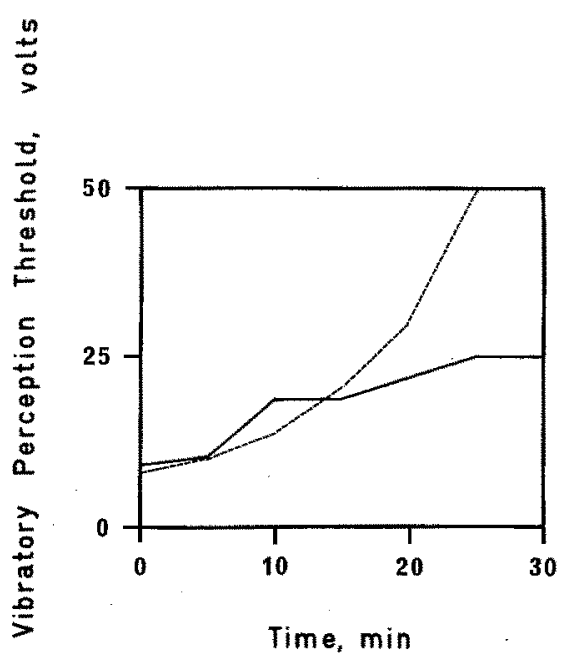

Fig. 3. Vibratory perception threshold in the great toe before and at $5 \mathrm{~min}$ intervals during $30 \mathrm{~min}$ of ischaemia in a patient in poor (full drawn line) and best control (dashed line). The ischaemic vibratory perception response is expressed as the ratio, volts $/ \mathrm{min}$, at termination. In this case the response during poor control was $25 / 30=0.83 \mathrm{~V} / \mathrm{min}$ and during best control $50 / 25=2.00 \mathrm{~V} / \mathrm{min}$

miosis) was $0.32 \pm 0.13$ (mean $\pm \mathrm{SD}$ ), whereas during poor control the degree of miosis was decreased by $0.15 \pm 0.03$ (mean \pm SEM) to $0.17 \pm 0.08(2 \mathrm{p}=$ 0.0011) (Fig. 4). Pupillary unrest in darkness was unchanged during poor control, but the unrest induced by continuous illumination was significantly less during poor control: the mean illuminated pupillary unrest measured in periods of $5 \mathrm{~s}$ was $0.81 \pm$ $0.43 \mathrm{~mm}^{2}$ during best control and reduced by $0.25 \pm$ $0.11 \mathrm{~mm}^{2}$ to $0.56 \pm 0.21 \mathrm{~mm}^{2}$ during poor control $(2 p=0.048)$, and the corresponding values for the periods of $15 \mathrm{~s}$ were $1.68 \pm 0.62 \mathrm{~mm}^{2}, 0.58 \pm$ $0.14 \mathrm{~mm}^{2}$ and $1.10 \pm 0.36 \mathrm{~mm}^{2}$, respectively $(2 \mathrm{p}=$ 0.0037 ) (Fig. 5).

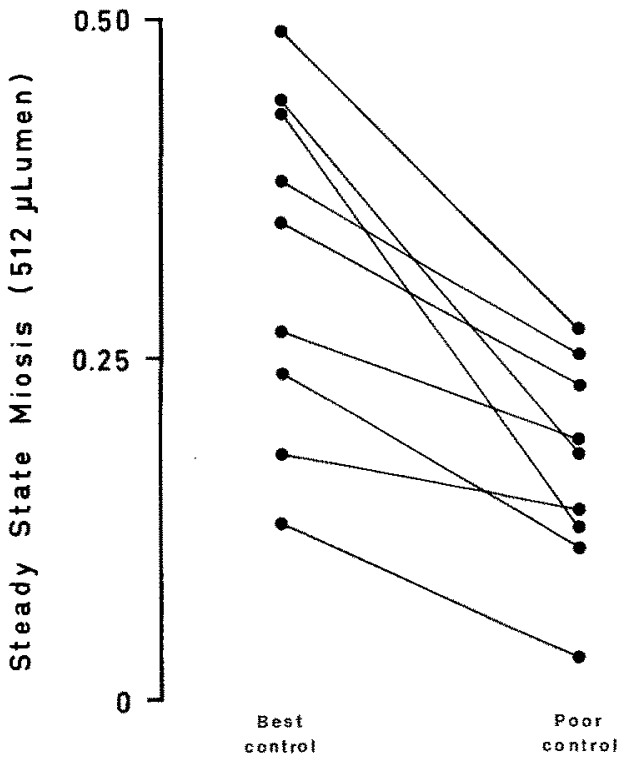

Fig. 4. Steady state miosis: Fractional reduction in pupil size caused by continuous illumination ( $512 \mu$ Lumen). Individual values during best and poor metabolic control are connected. Mean value during best control $0.32 \pm 0.13(\mathrm{SD})$ was reduced by $0.15 \pm$ 0.03 to $0.17 \pm 0.08$ (SEM) during poor control $(2 p=0.0011)$

The absolute decreases of both pupillary unrest and miosis during poor control were proportional to the initial values, subjects with the highest degree of miosis and unrest during good control had the greatest decreases during poor control (miosis, $\mathrm{r}=$ $0.80,2 \mathrm{p}=0.0048$; unrest in $15 \mathrm{~s}$ periods, $\mathrm{r}=0.82$, $2 \mathrm{p}=0.0033$; unrest in $5 \mathrm{~s}$ periods, $\mathrm{r}=0.89,2 \mathrm{p}=$ 0.00062 ).

It follows that the relative changes in miosis and unrest were less varying than the above absolute figures: the change in miosis was $47 \pm 6.4 \%$ (mean \pm SEM) $(2 \mathrm{p}=0.000077)$ and the change in unrest in $15 \mathrm{~s}$ periods was $32.2 \pm 5.9 \%(2 \mathrm{p}=0.00066)$ and unrest in $5 \mathrm{~s}$ periods was $22.6 \pm 7.8 \%(2 \mathrm{p}=0.020)$. 


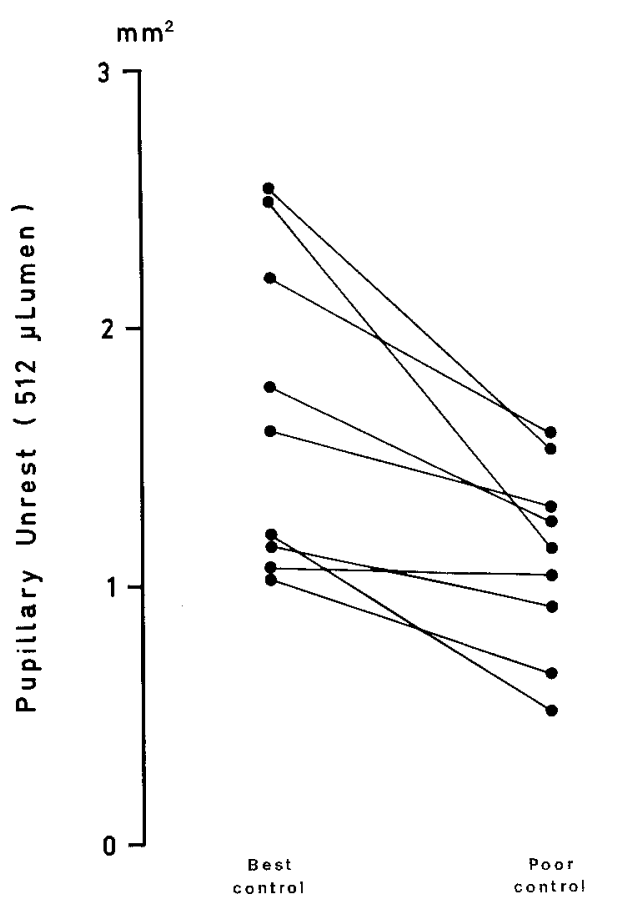

Fig. 5. Pupillary unrest in $512 \mu$ Lumen continuous light during best and poor metabolic control. Individual values are connected. The ordinate shows the standard deviation in $\mathrm{mm}^{2}$ of the pupil size within periods of $15 \mathrm{~s}$. Mean value during best control: $1.68 \pm$ $0.62 \mathrm{~mm}^{2}$ was reduced by $0.58 \pm 0.14 \mathrm{~mm}^{2}$ to $1.10 \pm 0.36 \mathrm{~mm}^{2}$ during poor control

The vibratory perception threshold increased more slowly under ischaemia during poor control $(2 \mathrm{p}=0.00042)$ and all patients had an ischaemic vibratory perception response well below the normal value of $2.00 \mathrm{~V} / \mathrm{min}$ (Table 1). During good control the mean value of the vibratory perception threshold before ischaemia was $9.5 \pm 2.0$ volts and the change during poor control was insignificant.

No correlations obtained between any absolute or relative pupillary measurements and the absolute values of or the changes in concentrations of blood glucose or other biochemical variables. There was also no correlations between the individual changes in the ischaemic vibratory perception threshold and pupillary changes. There was a significant positive correlation between pupillary unrest during continuous illumination and the miosis achieved, both during best $(\mathrm{r}=0.81,2 \mathrm{p}=0.0073)$ and worst $(\mathrm{r}=0.68$, $2 \mathrm{p}=0.046)$ control (Fig. 6).

There was a significant correlation between the changes in blood glucose and the ischaemic vibratory perception response, $\mathrm{r}=0.68,2 \mathrm{p}=0.046$ (Fig. 7).

Reversibility of the pupillary abnormalities was apparent in the five patients in whom poor control preceded best control. The degree of miosis was improved by $37.7 \pm 4.5 \%$ (mean \pm SEM) $(2 \mathrm{p}=$

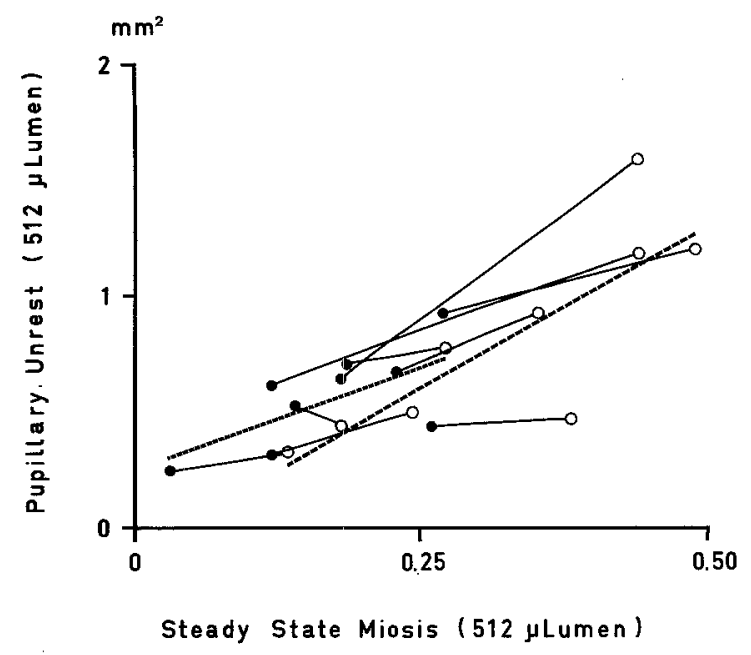

Fig. 6. The relationship between pupillary unrest measured during periods of $5 \mathrm{~s}$ and miosis. Individual values during poor $(\bullet)$ and best $(\mathrm{O})$ control are connected. The shortdashed and longdashed lines indicate regression lines in poor $(\mathrm{Y}=1.8 \mathrm{X}+0.3)$ and best control $(Y=2.8 X-0.1)$.

$0.0011)$ and the light induced unrest in $15 \mathrm{~s}$ periods was increased by $30.0 \pm 9.4 \%(2 \mathrm{p}=0.034)$ from poor to best control. The unrest in periods of $5 \mathrm{~s}$ was increased in a similar way after improved control, but the change did not reach the level of statistical significance.

\section{Discussion}

The present study has shown that the light induced unrest in the pupil diminishes during metabolic derangement and that this phenomenon can be reversed by improved control. Furthermore, the degree of miosis achieved by continuous illumination is reduced during metabolic derangement. The wellknown strong intraindividual inverse relationship between pupillary unrest and size [30] illustrated in Figure 2 and by the connecting lines in Figure 6, seems also therefore to hold between individuals, at least for moderate degrees of miosis. The pathophysiological basis for the two abnormalities during metabolic derangement remains to be explained, but it seems reasonable to suggest that they are the result of changes within the central autonomic nervous system. Studies by Stark and associates have shown that pupillary unrest is of central origin: the movements 


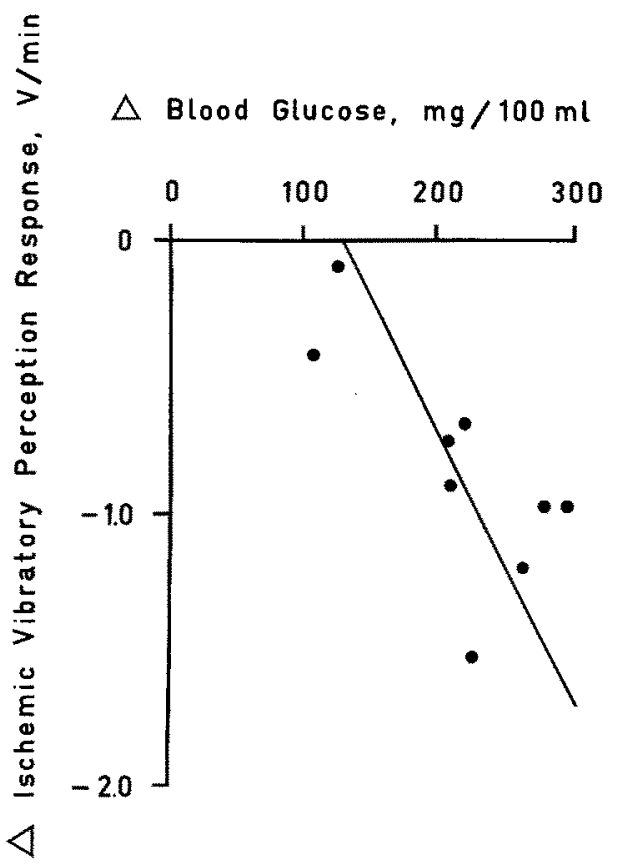

Fig. 7. The relationship between the poor-to-best difference of blood glucose (abscissa) and of ischaemic vibratory perception response (ordinate). The regression line is shown

are identical and synchronous in both eyes, $[30]$ and in cats neurones in the midbrain fire synchronously with the unrest [28].

The occurrence of optic neuritis has been described in poorly controlled diabetics [27], and the possibility of an afferent pupillary defect, which is indeed characterized by a diminished ability to maintain miosis under continuous illumination: "pupillary escape" or the Marcus Gunn phenomenon [18], has to be considered. The present findings cannot, however, be explained by a dysfunction of the retina or the optic nerve, since visual acuity, latency time, maximal contraction velocity and amplitude of the light response were unchanged. Even during recovery from optic neuritis with normalized visual acuity, there remains a reduction in reflex amplitude and a prolonged latency time $[6,23]$.

The only change during metabolic derangement in the light reflex was a delayed redilatation, which could indicate decreased sympathetic tone of the pupil or diminished supranuclear inhibition of the oculomotor nucleus due to tiredness. On the other hand the presence of diminished degree of miosis and unrest during continuous illumination cannot be explained by fatigue during the poor metabolic state, as this would be expected to lead to a smaller pupil and increased unrest $[20,36]$.

Increased sympathetic nervous activity as expressed by elevated plasma catecholamine concentrations can be found in poorly controlled diabetics, especially during ketoacidosis [5]. Alberti et al. [1] found, however, no change in catecholamine concentrations in diabetics who developed ketoacidosis after $41 \mathrm{~h}$ of insulin deprivation. Only two of the nine patients in the present study developed even slight ketoacidosis, and no indication of increased sympathetic nervous influence on the pupil was found since, for example, the resting pupil size in darkness was unchanged during poor control.

The present study has confirmed previous findings that diabetics retain vibratory perception during ischaemia longer during poor than good control, the so-called Steiness' paradox [31]. Furthermore, by employing a numerical expression of this phenomenon it has been possible to show that this abnormal response is quantitatively correlated to the rise in blood glucose.

Employing tests of cardiovascular reflex function Fraser et al. [7] and Campbell et al. [2] were unable to demonstrate reversible autonomic nervous abnormalities in newly diagnosed diabetics and in diabetics after episodes of ketoacidosis. The clear-cut reversibility of somatic nerve function was confirmed in both studies. Their conclusion that autonomic nerves may be less susceptible to acute metabolic damage is, however, conditional to the appropriateness and sensitivity of the above techniques. Page and Watkins [24] studied sinus arrhythmia at rest and during deep breathing in a group of diabetics during and after ketoacidosis and found no conclusive evidence of reversible autonomic abnormalities.

Little is known about the morphological and biochemical counterpart of the neurophysiological abnormalities in early human diabetes. In the animal model the changes in somatic nervous function are parallelled by axonal shrinkage and endoneurial oedema at an early stage in diabetes, and both the functional and the structural abnormalities are preventible by strict diabetic control $[15,16]$. Abnormal axonal transport of glycoproteins has been shown to occur early in these diabetic animals [26].

Reduced pupil size in darkness and diminished pupillary unrest has been demonstrated in long-term diabetics during ordinary metabolic control $[10,14$, 21] and in diabetics with autonomic neuropathy [29]. The light reflex, however, has been found to be normal when due regard is taken of the small pupil size, and equal sensitivity of the retina is ensured $[12,14]$. The pupillary abnormalities in long-term diabetes are not generally due to intrinsic stiffness of the iris tissue, but may be taken as an expression of autonomic nervous dysfunction [14]. The reduced fluctuation in the pupillary system in long-term diabetics probably corresponds to the lack of spontaneous variations in 
the foot blood flow [4] and in the heart rate $[13,35]$ which have been found in these patients.

The present study has thus shown that besides the previously well established reversible functional abnormalities of the somatic nervous system in early diabetes analogous changes influenced by the diabetic metabolic state occur also in the autonomic nervous system. How or whether these changes have an impact on the long-term abnormalities is a question, that still remains to be answered.

Acknowledgements. I thank Dr. J. M. Burrin, Department of Clinical Biochemistry and Metabolic Medicine, Royal Victoria Infirmary, Newcastle-upon-Tyne, for performing the 3-hydroxybutyrate analysis and Professor R. Keiding, Department of Clinical Chemistry, Aarhus University for his help with other biochemical analyses.

I am especially grateful to Dr. H. J. G. Gundersen and Professor K. Lundbæk for invaluable advice.

This work was supported by the Danish Medical Research Council.

\section{References}

1. Alberti KGMM, Christensen NJ, Iversen J, Ørskov H (1975) Role of glucagon and other hormones in development of diabetic ketoacidosis. Lancet I: 1307-1311

2. Campbell IW, Ewing DJ, Harrower ABD, Neilson JMM, Fraser DM, Baldwa VS, Murray A, Clarke BF (1976) Peripheral and autonomic nerve function in diabetic ketoacidosis. Lancet II: 167-169

3. Christensen NJ (1967) Notes on the glucose oxidase method. Scand J Clin Lab Invest 19: 379-384

4. Christensen NJ (1969) Spontaneous variations in resting blood flow, post-ischaemic peak flow and vibratory perception in the feet of diabetics. Diabetologia 5: 171-178

5. Christensen NJ (1979) Catecholamines and diabetes mellitus. Diabetologia 16: 211-224

6. Ellis CJK (1979) The afferent pupillary defect in acute optic neuritis. J Neurol Neurosurg Psychiatry 42: 1008-1017

7. Fraser DM, Campbell IW, Ewing DJ, Murray A, Neilson JMM, Clarke BF (1977) Peripheral and autonomic nerve function in newly diagnosed diabetes mellitus. Diabetes 26: $546-550$

8. Gregersen G (1967) Diabetic neuropathy: Influence of age, sex, metabolic control and duration of diabetes on motor conduction velocity. Neurology (Minneap) 17: 972-980

9. Gregersen G (1968) Variations in motor conduction velocity produced by acute changes of the metabolic state in diabetic patients. Diabetologia 4: 273-277

10. Gundersen HJG (1974) An abnormality of the central autonomic nervous system in long-term diabetes: absence of hippus. Diabetologia 10: 366

11. Gundersen HJG (1976) A new photostimulator and videopupillograph for quantitative neuroophthalmological studies. Ophthalmologica 172: 62-68

12. Gundersen HJG (1976) Nervous and muscular dynamics of the pupil in long-term diabetics. In: Bajaj JS (ed) Current topics in diabetes research (abstracts), IX Congress of the International Diabetes Federation. Excerpta Med Int Congr Series 413: 131

13. Gundersen HJG, Neubauer B (1977) A long-term diabetic autonomic nervous abnormality. Reduced variations in resting heart rate measured by a simple and sensitive method. Diabetologia 13: 137-140
14. Hreidarsson $A B$ (1979) Pupil motility in long-term diabetes. Diabetologia 17: $145-150$

15. Jakobsen J (1978) Peripheral nerves in early experimental diabetes. Expansion of the endoneurial space as a cause of increased water content. Diabetologia 14: 113-119

16. Jakobsen J (1979) Early and preventible changes of peripheral nerve structure and function in insulin-deficient diabetic rats. $\mathbf{J}$ Neurol Neurosurg Psychiatry 42: 509-518

17. Jordan WR (1936) Neuritic manifestations in diabetes mellitus. Arch Intern Med 57: 307-366

18. Levatin P (1959) Pupillary escape in disease of the retina or optic nerve. Arch Ophthalmol 62: 768-779

19. Lloyd B, Burrin J, Smythe P, Alberti KGMM (1978) Enzymic fluorometric continuous-flow assays for blood glucose, lactate, pyruvate, alanine, glycerol, and 3-hydroxybutyrate. Clin Chem 24: $1724-1729$

20. Lowenstein O, Loewenfeld I (1969) The pupil. In: Davson H (ed) The eye, vol III. Academic Press, New York, p 231-267

21. Lundbæk K (1968) Factors controlling blood glucose - with remarks on the effect of insulin on muscle. Proc R Soc Med 61: 807-811

22. Martin MM (1953) Diabetic neuropathy. A clinical study of 150 cases. Brain 76: 594-624

23. Müller-Jensen A, Zschocke S (1979) Possibilities of simultaneous analysis of phasic pupillary light reflex and visually evoked potentials. Electroencephalogr Clin Neurophysiol 47: 239-242

24. Page M, Watkins PJ (1976) Autonomic dysfunction in diabetic ketoacidosis. Lancet I: 963

25. Rundles RW (1945) Diabetic neuropathy. General review with report of 125 cases. Medicine (Baltimore) 24: 111-160

26. Sidenius P, Jakobsen J (1979) Axonal transport in early experimental diabetes. Brain Res 173: $315-330$

27. Skillern PG, Lockhart G (1959) Optic neuritis and uncontrolled diabetes mellitus in 14 patients. Ann Intern Med 51: 468-475

28. Smith JD, Masek GA, Ichinose LY, Watanabe T, Stark L (1970) Single neuron activity in the pupillary system. Brain Res 24: 219-234

29. Smith SE, Smith SA, Brown PM, Fox C, Sönksen PH (1978) Pupillary signs in diabetic autonomic neuropathy. Br Med J II: 924-927

30. Stark L (1968) Neurological control systems. Studies in bioengineering. Plenum Press, New. York, p 111-159

31. Steiness I (1961) Influence of diabetic status on vibratory perception during ischaemia. Acta Med Scand 170: 319-338

32. Steiness I (1957) Vibratory perception in diabetics. Acta Med Scand 158: $327-335$

33. Terkildsen AB, Christensen NJ (1971) Reversible nervous abnormalities in juvenile diabetics with recently diagnosed diabetes. Diabetologia 7: 113-117

34. Ward JD, Barnes CG, Fisher DJ, Jessop JD, Baker RWR (1971) Improvement in nerve conduction following treatment in newly diagnosed diabetics. Lancet I: 428-431

35. Wheèler T, Watkins PJ (1973) Cardiac denervation in diabetes. Br Med J IV: $584-586$

36. Yoss RE, Moyer NJ, Hollenhorst RW (1970) Pupil size and spontaneous pupillary waves associated with alertness, drowsiness, and sleep. Neurology (Minneap) 20: 545-554

Received: April 25, 1980,

and in revised form: December 1, 1980

Á. B. Hreidarsson

Second University Clinic of Internal Medicine

Kommunehospitalet

DK-8000 Aarhus C

Denmark 